\title{
Liver Transplantation in the Clinic - Progress Made During the Last Three Decades
}

\author{
Marco Carbone ${ }^{1}$, Giuseppe Orlando 2,3 , Brian Sanders 4 , \\ Christopher Booth2, Tom Soker2, Quirino Lai ${ }^{5}$, Katia Clemente', \\ Antonio Famulari ${ }^{6}$, Jan P. Lerut ${ }^{5}$ and Francesco Pisani ${ }^{6, *}$
}

\section{Introduction}

The World Health Organization calculates that over - six hundred and fifty million people worldwide suffer of some form of liver disease, including thirty million Americans. On a worldwide base, approximately one to two million deaths are accounted to liver related diseases annually. Around the globe, China has the world's largest population of Hepatitis B patients (approx. 120 million) with five hundred thousand people dying of liver illnesses every year (CDC, 2007; WHO, 2008). In the US alone, five hundred thousand critical liver problem episodes are reported every year requiring hospitalization with great burden to the patients and a huge cost to the health care system. In the European Union and United States of America alone, over eighty one thousand and twenty six thousand people died of chronic liver disease in 2006, respectively (CDC, 2007; Eurostat, 2007). In these patients, liver transplantation is presently the only proven therapy able to extend survival for end-stage liver disease. It is also the only treatment for severe acute liver failure and to some forms of inborn errors of metabolism.

The road to successful liver grafting in humans has been long and fraught with many obstacles. Experimental attempts at liver transplantation originally took place in the 1950s and 1960s, but human liver transplantation did not become a reality until 1963 (Starzl \& Demetris, 1990). Although unsuccessful, Dr. Starzl's attempt at liver transplantation was a milestone in surgery. However, it took nearly 20 years to develop a surgical procedure for orthotopic liver transplantation (OLT) that was safe to apply in humans. In 1983, the National Institutes of Health (NIH) held the Consensus Development Conference on Liver Transplantation. The most important outcome of this conference was OLT became an accepted therapeutic modality for some patients with end-stage liver disease (NIH, 1983). The ideal liver transplant candidate needed to comply with ten conditions (Table 1) as well

\footnotetext{
${ }^{*}{ }^{1}$ Hepatology Unit, Addenbrooke's Hospital, Cambridge, UK

${ }^{2}$ Wake Forest Institute for Regenerative Medicine, Winston Salem, NC, USA

${ }^{3}$ Department of General Surgery, Wake Forest Baptist Health, Winston Salem, NC, USA

${ }^{4}$ Wake Forest University School of Medicine, Winston Salem, USA

${ }^{5}$ Starzl Abdominal Transplant Unit, University Hospitals St.Luc, Université Catholique de Louvain, Brussels, Belgium

${ }^{6}$ Renal Failure and Transplant Unit - L'Aquila University, L'Aquila, Italy
} 
as ten absolute contraindications and five relative contraindications (Table 2). Taking into account the multitude of criteria for OLT, few patients were deemed eligible. Furthermore, the University of Pittsburgh was the only liver transplant center in the United States in 1983. Currently, 120 liver transplant centers in the United States are registered with the United Network for Organ Sharing (UNOS), the organization that manages the nation's organ transplant system, and 145 transplant centers from 24 European countries are participating in the European Liver Transplant Registry (ELTR). As reported in the UNOS database, 111,824 liver transplantations have been performed in the United States through December 2010 (UNOS, 2010). Likewise, 100,542 liver transplantations have been performed in Europe with an average of 5,562 transplantations per year in the past decade (ELTR, 2010).

\begin{tabular}{|c|}
\hline Young patient $<50$ years \\
No viral infection \\
No alcohol or drug abuse \\
Normal vessel state \\
No infection \\
No (advanced) malignancy \\
No cardiopulmonary or renal disease \\
No prior abdominal surgery \\
Ability to accept the procedure or understand its nature \\
Ability to accept costs of the procedure
\end{tabular}

Table 1. The ten conditions to be an ideal liver transplant candidate at the $1984 \mathrm{NIH}$ Consensus Conference

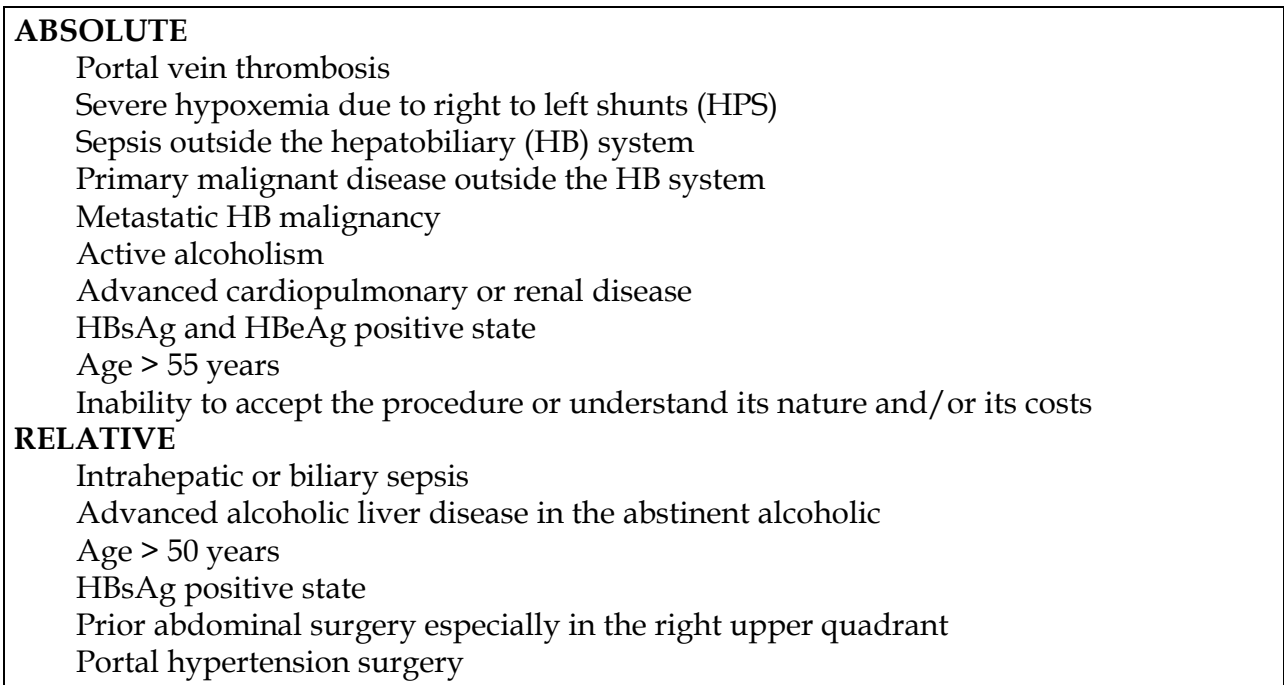

Table 2. The ten absolute and five relative contraindications to liver transplantation at the 1984 NIH Consensus Conference 
Since the first OLT was performed, the field has changed dramatically. Improvements in surgery, anaesthesia, immunosuppression, and control of infection have translated into increased access and better patient outcomes. In the pioneering days of OLT, triple-drug therapy (corticosteroids, azathioprine [AZA], and antilymphocyte globulin [ALG]) was used to prevent and treat rejection. The development of a powerful immunosuppressive agent, cyclosporine (CsA), in the late 1970s was one of the most significant events in modern transplantation. By 1984, all transplant centers in the United States used double therapy of corticosteroids and CsA as the maintenance immunosuppressive regimen. During the 1990s, tacrolimus (TAC) emerged as the mainstay maintenance immunosuppressive agent in OLT, with or without corticosteroids. More recently, mycophenolate mofetil (MMF) has replaced the use of AZA in many centers. Before the advent of CsA, 5-year survival after OLT was less than $20 \%$. Current survival rates 1, 3, and 5 years after liver transplantation in the United States are $88 \%, 80 \%$, and $75 \%$, respectively (UNOS, 2010).

Advancements in surgical techniques and technologies also account for the increased success of OLT. In particular, the standardization of biliary tract reconstruction, advances in retransplantation, and improvements in surgical technology help explain better patient outcomes. Examples of developments in technology include pump-driven veno-venous bypass that does not require recipient heparinization, rapid infusion, and autologous autotransfusion devices. Additionally, improved procurement and preservation techniques for the donor liver and increased insight into the management of potentially fatal complications have led to improved patient morbidity and mortality.

\section{Evolution of liver transplant indications}

Nowadays, liver transplantation is indicated for acute or chronic liver failure of any cause (Table 3).

Cirrhosis due to chronic hepatitis $\mathrm{C}$ infection is one of the most common indications for liver transplantation in the United States and Europe. Despite effective antiviral treatments including Pegylated Interferon, Ribavirin, and direct-acting antiviral agents (DAAs), this indication is likely to remain important for the coming decades given the large prevalence of chronic hepatitis $\mathrm{C}$ infection and the propensity of the disease to lead to cirrhosis and hepatocellular carcinoma (HCC) (Merion, 2010).

Chronic hepatitis B has become a less common indication, mostly due to the advent of universal vaccination. Additionally, dramatic improvements in the treatment of hepatitis B, such as the development of nucleoside/nucleotide analogues, has reduced the number of patients with chronic hepatitis B progressing to end-stage liver disease. However, in parts of the world where chronic hepatitis B is endemic, including much of Asia, this remains the most common indication (Perrillo, 2009).

Alcohol-related liver disease is an important indication for OLT in Western countries and is oftentimes associated with concomitant hepatitis $C$ infection. In the past, patients with alcohol-related liver disease and alcohol dependence were often refused access to liver transplantation due to unjust societal allocation of scarce donor organs. However, a careful assessment with the support of a health care professional experienced in the management of patients with addictive behavior is associated with low rates of recidivism after OLT (Lucey, 
1992). Nowadays, this indication has become more commonly accepted, as long as patients demonstrate sobriety of at least 6 months duration.

\begin{tabular}{|c|c|c|c|c|c|c|c|c|c|c|}
\hline \multicolumn{11}{|c|}{ Year of Transplant } \\
\hline $\begin{array}{c}\text { Primary } \\
\text { Diagnosis }\end{array}$ & 1998 & 1999 & 2000 & 2001 & 2002 & 2003 & 2004 & 2005 & 2006 & 2007 \\
\hline Total & 4,424 & 4,498 & 4,595 & 4,673 & 4,969 & 5,351 & 5,847 & 6,120 & 6,362 & 6,223 \\
\hline $\begin{array}{c}\text { Noncholestatic } \\
\text { cirrhosis }\end{array}$ & 2,790 & 2,899 & 2,956 & 2,973 & 3,091 & 3,151 & 3,514 & 3,709 & 3,732 & 3,547 \\
\hline $\begin{array}{l}\text { Cholestatic } \\
\text { liver disease }\end{array}$ & 563 & 499 & 475 & 471 & 492 & 513 & 510 & 467 & 552 & 555 \\
\hline $\begin{array}{c}\text { Acute hepatic } \\
\text { necrosis }\end{array}$ & 349 & 405 & 436 & 366 & 369 & 355 & 425 & 448 & 371 & 368 \\
\hline Biliary atresia & 214 & 188 & 161 & 172 & 164 & 175 & 187 & 179 & 143 & 174 \\
\hline $\begin{array}{c}\text { Metabolic liver } \\
\text { disease }\end{array}$ & 163 & 152 & 165 & 170 & 152 & 183 & 180 & 200 & 215 & 175 \\
\hline $\begin{array}{l}\text { Malignant } \\
\text { neoplasm }\end{array}$ & 98 & 87 & 84 & 142 & 3311 & 371 & 481 & 610 & 774 & 783 \\
\hline Other & 247 & 258 & 318 & 378 & 370 & 603 & 550 & 507 & 575 & 608 \\
\hline
\end{tabular}

a 2008 Annual Report of the U.S. Organ Procurement and Transplantation Network and the Scientific Registry for Transplant Recipients: Transplant Data 1998-2007. Rockville, MD: U.S. Department of Health and Human Services, Health Resources and Services Administration, Healthcare Systems Bureau, Division of Transplantation; 2009

Table 3. Primary Diagnosis of Deceased Donor Liver Transplant Recipients, 1998 to 2007a

Cholestatic liver disease is becoming an increasingly uncommon indication for OLT. Data from UNOS show that among cadaveric liver transplants in 1991, 18\% were for cholestatic liver disease, compared with $10 \%$ in 2000 and only $7.8 \%$ in 2008 (UNOS, 2010). The incidence and prevalence of primary biliary cirrhosis $(\mathrm{PBC})$ are steadily increasing whereas the absolute number of OLT performed for PBC is falling (UNOS, 2010; ELTR, 2010). Reasons for this decline in the number of transplants for $\mathrm{PBC}$ are not clear but may relate to a changing pattern of disease, increased rates of diagnosis, and more effective treatment. The number of transplants for primary sclerosing cholangitis (PSC) in western countries during the period 1995-2006 has remained stable and represents $8 \%$ of all liver transplants. In some areas that have a relatively low prevalence of hepatitis $C$ and alcoholic liver disease (ALD), such as the Scandinavian countries, PSC is the leading indication for OLT, accounting for $16 \%$ of the indications (Nordic Liver Transplant Registry, 2010).

Nonalcoholic fatty liver disease (NAFLD) is becoming one of the most common liver disorders in developed countries. Because this disorder can lead to cirrhosis in a number of 
patients and is associated with an increased risk of hepatocellular carcinoma (HCC), it is an increasingly frequent indication for liver transplantation (Burke, 2004). Considering the current obesity epidemic, NAFLD may become the most common indication for liver transplantation in the coming years.

Primary HCC is a unique and evolving indication for liver transplant. Initially, outcomes in liver transplantations for patients with unresectable HCC were not encouraging. Ninety percent of those transplanted for HCC developed recurrent disease within 2 years. As a result, HCC was considered a contraindication to transplantation for a number of years. Ongoing research on HCC post-transplant elucidated that important predictors of recurrence are tumor characteristics, such as tumor size, stage, and grade, number of nodules, micro- or macrovascular invasion, serum levels of alpha-fetoprotein, and demonstrated absence of extrahepatic spread. In 1996, Mazzaferro and colleagues defined the Milan criteria, which require a single tumor $\leq 5 \mathrm{~cm}$ in diameter or no more than three tumor nodules, each $\leq 3 \mathrm{~cm}$ in diameter. Liver transplant in patients meeting the Milan criteria have excellent outcomes and low recurrence rates (Mazzaferro, 1996). Augmentations to the Milan criteria are currently being debated in the liver transplant community. The San Francisco criteria, which require either a single lesion $\leq 6.5 \mathrm{~cm}$ or up to three lesions none of which is $>4.5 \mathrm{~cm}$ and with total tumor diameter $\leq 8 \mathrm{~cm}$, have been widely debated, but no consensus has yet emerged (Yao, 2001). Finally, more attention has been given to the role of downstaging by locoregional therapy for otherwise unsuitable candidates. Treatments to shrink nodules, including radiofrequency ablation, transcatheter arterial chemoembolization, and novel thermal and non-thermal techniques for tumor ablation offer strategies for subsequent transplantation in patients with more advanced lesions.

Many inborn errors of metabolism have been successfully treated with liver transplantation (Kayler, 2003).

Acute liver failure has long been considered an appropriate indication for liver transplant. Patients with fulminant hepatic failure should be referred to a transplant center as quickly as possible for critical care management. If given appropriate critical care support, many patients spontaneously recover. Patients predicted to have little chance of spontaneous recovery should undergo transplantation as soon as possible. New technologies using bioartificial liver devices including both a biological component and an artificial scaffold may offer some promises for patients with acute liver failure. However, these technologies have not become widely available yet, and therefore OLT remains an important treatment (Demetriou, 2004; Ellis, 1996).

\section{Historical contraindications to OLT}

\subsection{Absolute contraindications}

\subsubsection{Splanchnic venous thrombosis}

Splanchnic venous thrombosis and portal hypertension surgery are both part of the natural evolution of cirrhosis. Intra-operative mortality during OLT with these conditions was once nearly $50 \%$. Those that survived OLT oftentimes had morbid conditions that diminished the utility of the transplant. In recent times, several technical advances have been made to overcome this problem. Eversion thrombectomy is a good treatment option for a majority of 
patients with splanchnic venous thrombosis. If eversion thrombectomy is not possible, a free iliac interposition graft between the allograft portal vein and the superior mesenteric vein is indicated. Sometimes it is possible to connect the allograft portal vein to a collateral vein. In cases of extended splanchnic thrombosis, cavo-portal hemi-transposition or combined liverintestinal transplantation are the last resorts for treatment (Lerut, 1997).

\subsubsection{Hepatopulmonary Syndrome (HPS)}

HPS is defined as a pO2 $<70 \mathrm{mmHg}$ in an upright position. It is present in up to $20 \%$ of cirrhotic patients. Even in cases where oxygen saturation is below $50 \mathrm{mmHg}$, this situation can be reversed by a successful OLT. The post-transplant recovery is usually more complicated necessitating adapted respiratory care. The pre-transplant baseline macroaggregated albumin shunt fraction may indicate the limits of correction following OLT (Starzl, 1990).

\subsubsection{Sepsis outside the hepatobiliary system}

Active extra-hepatic infection compromises outcomes of OLT. Nonetheless, transplantation can be performed successfully if the infection is confined to the lungs or the ascites and does not cause hemodynamic instability (Starzl, 1990). Post-transplant care is usually much more prolonged and expensive if the patient has sepsis outside the hepatobiliary system.

\subsubsection{Primary malignant disease outside the hepatobiliary system}

Based on the embryological development theory, Starzl advocated the 'en block' or 'cluster transplant' in order to treat extended hepatobiliary malignancies and liver metastases from neuroendocrine tumors. Although initial success was promising, longterm results were disappointing. (Lerut, 2007, 2011; Starzl, 1990).

Pre-OLT malignancies or malignancies discovered incidentally during the OLT-procedure are no longer contraindications to OLT as shown by the Kings' College study. Metastatic hepatobiliary malignancy is an emerging indication for OLT. After successful chemotherapeutic treatment of hepatic and thoracic tumor involvement in children with hepatoblastoma, excellent results have been obtained with OLT. Similarly, excellent longterm results have been obtained for epithelioid hemangio-endothelioma. In the latter group some centers propose sequential or simultaneous hepatopulmonary transplantation (Lerut, 2007).

The role of OLT in the treatment of neuroendocrine tumors with hepatic involvement is continuously evolving. Excellent OLT results can be obtained in select, young ( $<50$ years) patients after R0 resection of the primary tumor for more than six months prior to transplant. Furthermore, if the primary lesion has favorable tumor biology (as expressed by a Ki67 index of $<5-10 \%$ ) and has a portal vein drainage, results are significantly improved (Bonaccorsi-Riani, 2010).

It is evident that all oncologic patients that undergo OLT will benefit from adapted immunosuppression. Minimization of immunosuppression and use of the m-TOR inhibitor, rapamycin, are of paramount importance. Rapamycin has antitumor activity based on antiangiogenic properties. 
The most recent development in the field of OLT is the treatment of metastatic colorectal malignancy. The Oslo-SECA (SEcondary CAncer) study indicates that OLT will have a role in the treatment of colorectal metastases on the condition that adapted chemotherapy and immunosuppression are employed after the transplant procedure. Preliminary results obtained in the Oslo-SECA cases show nearly 50\% 5-year survival after OLT (Foss, 2011).

\subsubsection{Alcohol abuse}

OLT in active alcoholic patients has always been discussed heavily within the medical community (Starzl, 1990). The 'six month abstinence rule' is not generally enforced, and some French groups even advocate OLT in cases of severe acute alcoholic hepatitis (Mathuri, 2005).

\subsubsection{Drug abuse}

Although also heavily debated, some groups in New York showed that OLT can be successful in recipients on methadone maintenance.

Both alcohol and drug abusers need exceptionally tight follow-up during the pre- and posttransplant period. It is of utmost importance to take familial, professional, and social conditions into consideration in these potential patients (Starzl, 1990).

\subsubsection{Advanced cardiopulmonary disease}

Two-staged cardiac and hepatic transplantion is becoming more frequent (Starzl, 1990). Several case reports have been published about simultaneous liver and heart transplantation in the context of familial amyloid polyneuropathy (FAP) and hemochromatosis. Simultaneous OLT with coronary, valvular, or arrythmia surgery has also been reported. These surgeries are complex and have stimulated major interest in both cardiovascular and hepatic experts of transplant centers.

\subsubsection{Viral infections}

Viral cirrhosis was once an absolute contraindication to OLT because of the universal recurrence of the disease in the liver allograft (Lerut, 1998). The landmark paper of Samuel in 1993 showed that adequate antiviral prophylaxis using specific anti-HBs antibodies protects the allograft from reinfection (Samuel, 1993). Further improvement has been achieved by combining nucleoside and nucleotide analogues with immunoglobulins. This prophylactic combination was able to reduce the incidence of allograft reinfection from $100 \%$ to $5 \%$. Moreover, those with $\mathrm{HBV}$ gain an immunologic advantage from immunoglobulin treatment due to immunoglobulins producing a tolerogenic effect on dendritic cells.

\subsubsection{Age}

Increasing numbers of transplants are done in patients aged over 65 and 70 years of age (Starzl, 1990). The initial Pittsburgh results have now been confirmed by most transplant centers. 


\subsubsection{Inability to accept or understand the procedure}

OLT is accessible to patients in all levels of society. Successful OLT has been reported in Down Syndrome patients and in drug abusers. Adequate preparation by medical, paramedical, and clinical coordinator teams is of utmost importance in complicated clinical scenarios.

\subsection{Relative contraindications}

\subsubsection{Intra-hepatic or biliary sepsis}

Chronic biliary infection is frequent in Caroli disease, primary sclerosing cholangitis, and secondary sclerosing cholangitis. Because the infection is usually confined to the liver, outcome of OLT is excellent as transplantation removes the source of the infection. OLT is especially valuable in these patients as it dramatically improves their quality of life.

\subsubsection{Advanced liver disease in abstinent alcoholic patients}

The Model for End-Stage Liver Disease (MELD) scoring system aims to reduce liver waitlist mortality by transplanting sicker patients more rapidly. Abstinent alcoholics frequently belong to the sickest patient groups. Nowadays, OLT is a very good indication in such patients if the recipient remains abstinent and is compliant. If the recipient remains abstinent, alcoholic cirrhosis is one of the best indications for OLT as this is the only disease that does not recur in the allograft. Moreover, abstinent alcoholics that receive OLT offer a unique opportunity to study the effect of immunosuppression withdrawal without primary disease involvement in the allograft.

\subsubsection{Previous abdominal surgery}

Many transplant recipients have undergone previous abdominal and right upper quadrant surgery. These interventions can compromise the transplant procedure. Thus, exploratory or staging laparotomies as well as unnecessary cholecystectomies and cyst fenestrations should be avoided in future OLT patients. Interventional radiology procedures such as the Transjugular Intrahepatic Portosystemic Shunt (TIPSS) are preferred in potential OLT recipients instead of portal hypertension surgery. In cases where portal hypertension surgery cannot be avoided, meso-caval or spleno-renal shunts are the preferred options leaving the hilar region intact.

\subsubsection{HIV infection}

HIV patients that are well controlled on Highly Active Antiretroviral Therapy (HAART) are generally not contraindicated for OLT. The indication for OLT relates more so to concomitant $\mathrm{HCV}$ and/or HBV infection. Co-infected patients are at higher post-OLT infectious risk. Particular attention should be given to the interaction between anti-viral drugs and calcineurin inhibitors.

\subsubsection{Positive HBsAg status}

See above. 


\section{Future perspectives}

Criteria for placement on the waiting list have become more quantitative. Continuous refinement of the allocation system will improve the management of the waiting list (Metsellaar, 2011).

Alternative techniques such as split liver transplantation (SLT) and living donor liver transplantation (LDLT) will allow for expansion of the allograft pools. The bipartition of the liver is especially important in pediatric patients for whom size-matched whole liver allografts are scarce. Split grafts have been associated with reduction in the risk of death on the pediatric waiting list. However, SLT is much less successful in the adult-adult SLT. Donor selection for splitting and technical and logistical expertise to decrease total ischemia time are important factors in successful transplantation. A better understanding of the liver anatomy and improving surgical skills have allowed living liver donation to become a routine procedure in some centers. Given the major risks of the operation required for the donor, whether this procedure will ever find wide application is unclear.

As there will always be more potential recipients than donors, many researchers are working in the field of artificial tissue engineering and regenerative medicine (RM) (Orlando, 2011a, 2011b, 2011c, 2011d, 2012a, 2012b, 2012c). RM holds the promise of regenerating tissues and organs by either stimulating previously irreparable tissues to heal themselves, by treating liver disease with cell therapies, or by manufacturing tissues ex vivo using extracellular matrix (ECM) scaffolds.

This last approach, uses ECM scaffolds that have an intact but decellularized vascular network that is repopulated with autologous or allogeneic stem cells and/or adult cells. Liver ECM scaffolds may be produced from humans or animals. In the latter case, human cells are used to repopulate a scaffold of animal origin, coining a new concept called semi-xenotransplantation (Orlando, 2011a, 2011b). Importantly, preemptive transplantation with regenerated tissues will improve outcomes, especially in cases of metabolic and cystic liver disease.

Future progress in the medical treatment of oncology will enhance outcomes in OLT (Lerut, 2007, 2011; Bonaccorsi-Riani, 2010, Foss, 2011). As treatments of vascular tumors, advanced hepatocellular cancer, cholangiocellular cancer, neuroendocrine tumors, and colorectal liver metastases improve, indications for OLT in the $21^{\text {st }}$ century will become more inclusive of advanced oncologic disease states.

Combined organ transplantation is becoming more frequent as many liver diseases are accompanied by renal function impairment. Nowadays, $15 \%$ of all liver recipients have combined liver-kidney transplantation.

Transplant teams should focus more on late morbidity and mortality. Currently, the majority of long-term survivors die from infectious disease, cardiovascular disease, or cancer while having a functional graft. This mortality is directly related to the strength of the maintenance immunosuppression. Minimization or even withdrawal of immunosuppressive protocols must become a priority in organ transplantation (Lerut, 2003, 2008). Unfortunately, tolerance protocols are frequently based on a trial and error approach, as good markers to predict tolerance are not yet available (Lerut, 2006). As the liver is an immunoprivileged organ with relatively high resistance against immune responses, liver recipients should be at the forefront of this research. 


\section{Conclusion}

Since the first transplantation was performed much progress has been made in the field of OLT. Indications for liver transplant have evolved to include previously contraindicated conditions such as those with hepatocellular carcinoma and alcohol-related liver disease. All but one (active sepsis outside the biliary system) contraindication to OLT has been eliminated. As a result, more than 200,000 patients have been transplanted, many with excellent long-term success. With indications to transplantation increasing and contraindications waning, many more patients will be transplanted in the future.

The future of liver transplantation will be no less challenging for its practitioners. The main challenge is the shortage of organs, and many strategies are in place to address this problem. In the near future, immunologic discoveries will allow for an immunosuppression-free state of many recipients. This will guarantee better quality of life and similar survival expectancy as non-transplanted patients. Regenerative medicine technology applied to liver transplantation has the potential to meet the two major needs: namely, the identification of a potentially inexhaustible source of livers and an immunosuppression-free state. In the ideal scenario, livers will be manufactured from autologous cells with no need for anti-rejection therapy.

\section{References}

Bonaccorsi-Riani E., et al. (2010). Liver transplantation and neuroendocrine tumours: lessons from a single centre experience and from the literature review Transplant Int 23, 2010, 668-678.

Burke A, Lucey MR. (2004). Non-alcoholic fatty liver disease, nonalcoholic steatohepatitis and orthotopic liver transplantation. Am J Transplant, 4, 5, 686-693.

CDC (2007). Centers for Disease Control and Prevention Database.

Demetriou AA, Brown RS, Busuttil RW et al. (2004). Prospective, randomized, multicenter, controlled trial of bioartificial liver in treating acute liver failure. Ann Surg, 239, 2004,660 .

Ellis AJ, Hughes RD, Wendon JA, Dunne J, Langley PG, Kelly JH, Gislason GT, Sussman NL, Williams R. (1996). Pilot-controlled trial of extracorporeal liver assist device in acute liver failure. Hepatology, 24, 1996, 1446-51.

European Liver Transplant Registry. Available at: www.ELTR.org.

Eurostat (2007). Eurostat's Harmonised Regional Statistical Database.

Foss A, Adam R, Dueland S. (2011) Liver transplantation for colorectal metastases: revisiting the concept Transplant Int. 23, 2011, 679-685.

Kayler LK, Rasmussen CS, Dykstra DM, et al. (2003). Liver transplantation in children with metabolic disorders in the United States. Am J Transplant, 3, 2003, 334-339.

Lerut J., Mazza D.,Van Leeuw V.,Laterre P.F.,Donataccio M.,De Ville de Goyet J. et al. (1997). Adult Liver transplantation and abnormalities of splanchnic veins: experience in 53 patients. Transplant Int 10, 1997, 125-132.

Lerut J et al. (1998). Liver transplantation and HBV-related disease: adequate immunoprophylaxis and delta co-infection as major determinants of long-term prognosis. J Hepatol 30, 1998, 706-714. 
Lerut J. (2003). Avoiding steroids in solid organ transplantation. Transplant Int 16, 2003, 213 224.

Lerut J, Sanchez-Fueyo A. (2006).An appraisal of tolerance in liver transplantation. Am J Transplant 6, 2006, 1774-1780.

Lerut, et al. (2008). Tacrolimus monotherapy in liver transplantation:one-year results of a prospective, randomized, double-blind, placebo-controlled study. Ann Surg 248, 2008, 956-967.

Lerut J., Weber M., Orlando G., Dutkowski P. (2007) Vascular and rare liver tumors: A good indication for liver transplantation? J Hepatol 47, 2007, 466-475.

Lerut J., Ciccarelli O., Julliard O, Lannoy V., Gofette P. (2011) Hepatocelluar cancer and liver transplantation: a western experience in : Multidisciplinary Treatment of Hepatocellular Carcinoma. Springer Verlag Eds : Vauthey, Brouquet.

Lucey MR,Merion RM, Henley KS, et al. (1992) Selection for and outcome of liver transplantation in alcoholic liver disease. Gastroenterology, 102,5, 1992, 1736-1741.

Mathuri P. (2005). Is alcoholic hepatitis an indication for transplantation? Current management and outcomes. Liver Transplation, 11, 2005, S21.

Merion R. (2010).Current Status and Future of Liver Transplantation. Semin Liver Dis 30, 2010, 411-421.

Mazzaferro V, Regalia E, Doci R, et al. (1996).Liver transplantation for the treatment of small hepatocellular carcinomas in patients with cirrhosis. N Engl J Med, 334,11,1996,693699.

Metselaar H.J, Lerut J., Kazemier G. (2011). The true merits of liver allocation according to MELD scores: survival after transplantation tells only one side of the story Transplant Int, 10, 2011.

National Institutes of Health (NIH). (1983) NIH Consensus Development Conference Statement: Liver transplantation. Hepatology. 4(1S), 1983, 107S-110S.

Nordic Liver Transplant Registry. Available at:www.scandiatransplant.org.

Orlando G, Domínguez-Bendala J, Shupe T, Bergman C, Bitar KN, Booth C, Carbone M, Koch K, Lerut JP, Neuberger J, Petersen BE, Ricordi C, Atala A, Stratta RJ, Soker S. (2012). Cell and Organ Bioengineering Technology as Applied to Gastrointestinal Diseases. GUT in press.

Orlando G, Wood KJ, De Coppi P, Baptista PM, Binder KW, Bitar KN, Breuer C, Burnett L, Christ G, Farney A, Figliuzzi M, Holmes JH IV, Koch K, Macchiarini P, MirmalekSani SH, Opara E, Remuzzi A, Rogers J, Saul JM, Seliktar DS, Shapira-Schweitzer K, Smith T, Solomon D, Van Dyke M, Yoo JJ, Zhang Y, Atala A, Stratta RJ, Soker S. (2012). Regenerative medicine as applied to general surgery. Ann Surg, in press.

Orlando G, Wood KJ, Soker S, Stratta RJ. (2011). How regenerative medicine may contribute to the achievement of an immunosuppression-free state. Transplantation, 92, 8, 2011, 36-8.

Orlando G. (2011). Transplantation as a subfield of regenerative medicine. An interview by Lauren Constable. Expert Rev Clin Immunol, 7, 2011, 137-141.

Orlando G, Wood KJ, Stratta RJ, Yoo J, Atala A, Soker S. (2011). Regenerative medicine and organ transplantation: Past, present and future. Transplantation 91, 2011, 1310-7.

Orlando G, Baptista P, Birchall M, Di Coppi P, Farney A, Opara E, Rogers J, Seliktar D, Shapira-Schweitzer K, Stratta RJ, Atala A, Wood KJ, Soker S. (2011). Regenerative 
medicine as applied to solid organ transplantation: current status and future development. Transpl Int, 24, 2011, 223-232.

Orlando G. (2012). Immunosuppression-free transplantation reconsidered from a regenerative medicine perspective. Exp Rev Clin Immun 2012, in press.

Perrillo R. (2009). Hepatitis B virus prevention strategies for antibody to hepatitis B core antigen-positive liver donation: a survey of North American, European, and AsianPacific transplant programs. Liver Transpl, 152, 2009, 223-232.

Starzl T.E., Demetris A.J (1990). Liver Transplantation. Year Book Medical Publishers, Inc. Chicago, USA

United Network for Organ Sharing. Available at: www.UNOS.org

WHO (2008). World Health Organization - Global Burden of Disease: 2004 update (2008). In WHO publications. 


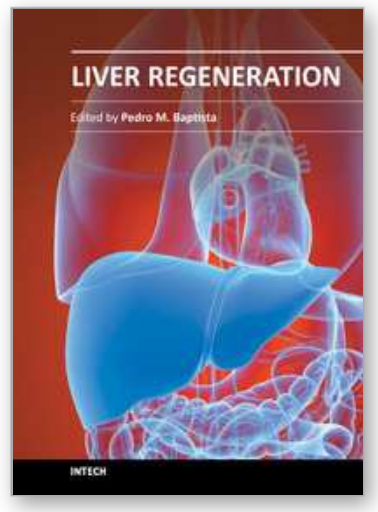

\author{
Liver Regeneration \\ Edited by PhD. Pedro Baptista
}

ISBN 978-953-51-0622-7

Hard cover, 252 pages

Publisher InTech

Published online 16, May, 2012

Published in print edition May, 2012

Doctors and scientists have been aware of the "phenomenom" of liver regeneration since the time of the ancient Greeks, illustrated by the mythic tale of Prometheus' punishment. Nevertheless, true insight into its intricate mechanisms have only become available in the 20th century. Since then, the pathways and mechanisms involved in restoring the liver to its normal function after injury have been resolutely described and characterized, from the hepatic stem/progenitor cell activation and expansion to the more systemic mechanisms involving other tissues and organs like bone-marrow progenitor cell mobilization. This book describes some of the complex mechanisms involved in liver regeneration and provides examples of the most up-to-date strategies used to induce liver regeneration, both in the clinic and in the laboratory. The information presented will hopefully benefit not only professionals in the liver field, but also people in other areas of science (pharmacology, toxicology, etc) that wish to expand their knowledge of the fundamental biology that orchestrates liver injury and regeneration.

\title{
How to reference
}

In order to correctly reference this scholarly work, feel free to copy and paste the following:

Marco Carbone,Giuseppe Orlando, Brian Sanders, Christopher Booth, Tom Soker, Quirino Lai, Katia Clemente, Antonio Famulari, Jan P. Lerut and Francesco Pisani (2012). Liver Transplantation in the Clinic Progress Made During the Last Three Decades, Liver Regeneration, PhD. Pedro Baptista (Ed.), ISBN: 978953-51-0622-7, InTech, Available from: http://www.intechopen.com/books/iver-regeneration/livertransplantation-in-the-clinic

\section{INTECH}

open science | open minds

\section{InTech Europe}

University Campus STeP Ri Slavka Krautzeka 83/A

51000 Rijeka, Croatia

Phone: +385 (51) 770447

Fax: +385 (51) 686166

www.intechopen.com

\section{InTech China}

Unit 405, Office Block, Hotel Equatorial Shanghai

No.65, Yan An Road (West), Shanghai, 200040, China 中国上海市延安西路65号上海国际贵都大饭店办公楼 405 单元

Phone: +86-21-62489820

Fax: +86-21-62489821 
(C) 2012 The Author(s). Licensee IntechOpen. This is an open access article distributed under the terms of the Creative Commons Attribution 3.0 License, which permits unrestricted use, distribution, and reproduction in any medium, provided the original work is properly cited. 